\title{
A DSGE Model of Slovakia with Frictional Labor Market and Monetary Regime Switch
}

\section{Adam Pápai ${ }^{1}$}

\begin{abstract}
The aim of this paper is to examine the dynamical and structural characteristics of Slovakia using a dynamic stochastic general equilibrium model augmented with search and matching mechanisms and other forms of frictions. I implement a switching mechanism to account for the monetary regime change in Slovakia in 2009. My focus lies in the investigation of labor market rigidities that affect the macroeconomic variables. I also examine the long term impact of the recession in 2009 on the Slovak economy. My findings are as follows. Firstly, based on parameter estimates, I identify significant labor market frictions present in the Slovak Republic. Secondly, my results capturing the historical evolution of key macroeconomic variables support the view that the recession in the examined small open economy was mainly caused by shocks originating in the foreign sector. Thirdly, the monetary authority can influence the labor market variables through its transmission channels relatively effectively; and lastly, I discovered that the recession decreased the Slovak economy's flexibility. While the results of estimations on two sub-samples are quite similar for most of the structural parameters, an increase in price and wage stickiness is observable.
\end{abstract}

Key words: DSGE model, labor market, search and matching, Slovakia, small open economy, rigidity, unemployment

JEL Classification: C51, E24, E52, J60

Received: 20 April 2017 / Accepted: 1 August 2017 / Sent for Publication: 12 September 2017

\section{Introduction}

The role of the labor market is crucial for the development of the economy. Countries with better conditions of the labor market usually have lower rates of unemployment and better morale of workers. Furthermore, this market is closely linked to households, so any changes affect people directly. It is therefore desirable to investigate this sector of the economy.

Nowadays, the dynamic stochastic general equilibrium (DSGE) models play a crucial part in the world of macroeconomic modelling. In the mid-2000s, economists started

\footnotetext{
${ }^{1}$ Masaryk University, Faculty of Economics and Administration, Department of Economics, Lipová 41a, 60200 Brno, mail: papai@ mail.muni.cz
}

(c) 2017 by the authors; licensee Review of Economic Perspectives / Národohospodárský obzor, Masaryk University, Faculty of Economics and Administration, Brno, Czech Republic. This article is an open access article distributed under the terms and conditions of the Creative Commons Attribution 3.0 license, Attribution - Non Commercial - No Derivatives. 
including various specifications of the labor market in the models. Together with the incorporation of frictions, increasingly more complex models are used today to capture the cyclical properties of the economy. The main advantage of the DSGE models is that they are resilient to the Lucas critique. The DSGE models are structural, micro-founded models with deep parameters. As Hurtado (2013) points out, if they are well specified, they are not affected by policy changes. Contrary to other types of models, the interpretation of structural parameters and shocks is more straightforward. Also, because they are general equilibrium models, all variables, not just some of them or a particular market only, are assumed to be in equilibrium simultaneously.

In this paper, I adapt the DSGE model developed by Albertini et al. (2012) for the economy of New Zealand to match the properties of the Slovak economy. One of the key differences between these two economies is the change of monetary policy in 2009 in Slovakia which came with the adoption of the euro. This required an introduction of a monetary regime switch into the model. I aim to examine the dynamical and structural properties of the Slovak economy. My focus lies in the investigation of the labor market - mainly in the identification of its flexibility by estimating parameters determining the degree of rigidities. I also aim to capture the slowdown of wage growth and the long period of high unemployment and a low vacancy rate during the recession.

There are a few models assessing the Slovak economy. Zeman and Senaj (2009) describe a SOE DSGE model that is designed to simulate the dynamic behavior of the country's economy. All of the key macroeconomic variables are incorporated into the model to ensure better results of simulations and a wider explanatory potential. The model also contains price and wage rigidities to improve the dynamic behavior of the model variables. The authors evaluate the appropriateness of the model through a comparison of simulated second moments with moments from the data, impulse responses to shocks, and replicating historical data.

The first DSGE model of Slovakia estimated using Bayesian techniques was created by Senaj et al. (2010). They use a two-country model suitable for a policy analysis of the Slovak economy as a part of the euro area. Their specification of the model allows switching between two types of monetary regimes which have been used in Slovakia at some point. In the first regime, the model is specified for two countries with autonomous monetary policies, while in the second regime, the two countries constitute the euro area with a common monetary policy. In their comparison of the two regimes, Senaj et al. find that the absence of an exchange rate adjustment tool of the monetary policy in the monetary union regime produces the same shocks affecting the economy in different volumes.

The focus of Múčka and Horváth (2015) lies in the examination of the Slovak fiscal policy. Their study covers a labor market with a frictional wage setting, and thoroughly inspects the fiscal part of the economy. The authors conducted several analyses of various strategies used to permanently lower the public debt from an elevated level. Cuts in the government wage bill are the least harmful to the real economy, especially if the economy is in a recession. The labor income tax increases are, out of all the tax measures, the most harmful to the growth in the long term.

Němec (2013) in his paper compares the Slovak labor market with the Czech one. He estimates a SOE model using Bayesian techniques and discovers a low bargaining pow- 
er of workers in both economies, which suggests a low participation in trade unions. According to the results, the unemployment benefits are significantly higher in the Czech Republic. On the other hand, the cost of creating an additional vacancy is larger in Slovakia. Altogether, the model supports the view that the structure of the Slovak and the Czech labor market is similar.

My research expands the literature on DSGE in Slovakia with a model containing a detailed description of the labor market and a monetary regime switch. My results suggest that the Slovak economy faces considerable frictions which became stronger after the crisis of 2008. The impact of different shocks on the examined variables before 2009 is more noticeable because of the higher flexibility. Furthermore, I have identified a standard transmission mechanism of the monetary policy through which the monetary authority can affect the real economy, including labor market variables. I also confirm the small size and openness of the Slovak economy, since the foreign shocks play such a significant role in the historical development of the country's domestic variables. However, the model suggests only a weak link between the labor market and rest of the economy.

The structure of this paper is organized as follows. Firstly, a brief glimpse into the economic background of Slovakia is presented with a focus on the labor market. Then, the applied SOE DSGE model is outlined in its log-linear form. Next, the data obtained for my estimation are described together with the data transformation processes. This section also contains the calibration of fixed parameters and the prior distribution setting of estimated parameters. This is followed by an insight into the estimation methodology. The next section contains the results of my investigation of the Slovak economy. The final section concludes the paper with a summary of my findings.

\section{Economic background}

The Slovak labor market has experienced a few ups and downs in the past 15 years. Figure 1 captures the development of output, nominal exchange rate and key labor market variables. The decline of unemployment during 2002 and the first half of 2003 can be credited to the reconstruction and privatization of the banking sector, which led to an increasing foreign direct investment. These investments also led to an increase in the number of vacancies and real wage. Another reforms in taxation, labor market and social policy caused a completely opposite development over the next four quarters. However, these structural changes together with the entry of Slovakia to the European Union later on resulted in a significant improvement of the situation around the labor market. In the following four years, until the Great Recession in 2009, the real hourly wage increased by more than one euro, the vacancy rate almost doubled and the unemployment rate was cut in half. This favorable development on the labor market was accompanied by a substantial economic growth, which put Slovakia among the fastest growing economies in the European Union. 
Figure 1 Selected data of the Slovak economy
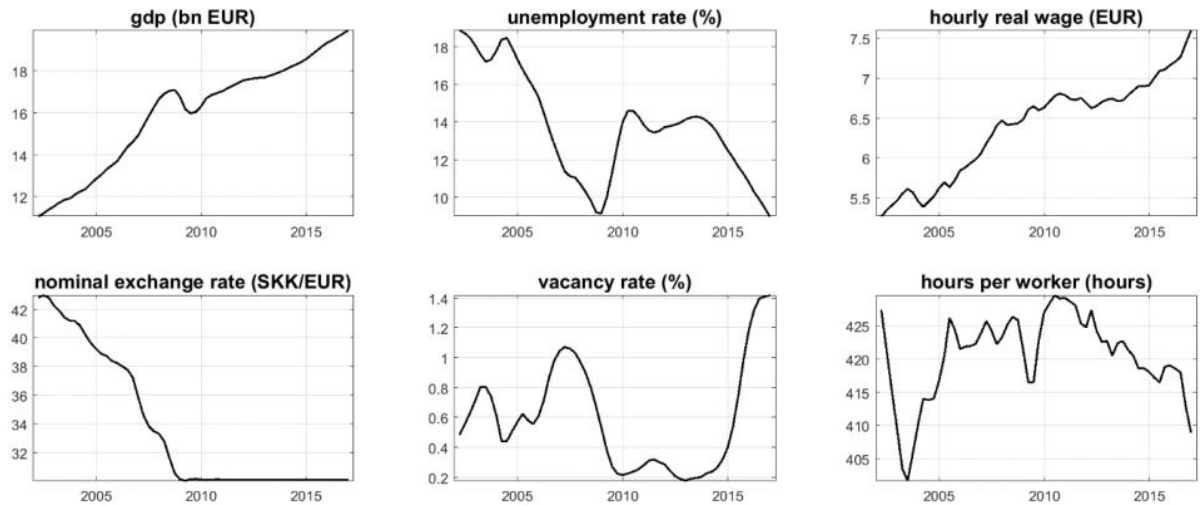

Source: National Bank of Slovakia, authors' computations.

Nonetheless, the upcoming worldwide recession had a major impact on the small open economy of Slovakia. While the output plummeted, the unemployment rate rose rapidly. Within one year of the recession, it increased from 9.1 to $14.6 \%$. The decrease of vacancy rate had started even sooner, in 2007. Within three years it dropped by more than $2 / 3$ from $1.1 \%$ to less than $0.3 \%$. The recovery of the economy was slow and took several years. Until 2014, the unemployment rate remained around $14 \%$, only with some minor changes. The vacancy rate had stayed under the $0.5 \%$ value until 2015 . Also, the wages slowed down their increase rapidly in the period from 2009 to 2015 . This suggests that the recession led to a decrease in the flexibility of the Slovak labor market. Since 2015, the revival of the Slovak economy has sped up significantly. The unemployment rate has reached its levels from before the crisis. In 2015 and 2016, the vacancy rate quadrupled and reached its historical peak. Moreover, the increase of real hourly wage has picked up as well in the last few years. The recent developments reflect the improving effectivity of the Slovak labor market.

\section{Model}

The presented New Keynesian DSGE SOE model was originally compiled by Albertini et al. (2012) and estimated for the small open economy of New Zealand. I present the model adjusted with my own modifications which are summarized at the end of this section. The model consists of homogenous households and firms. There is no capital present; the only input of production is labor. The changes in the labor market are captured by varying hours worked (intensive margin) and the decision of whether or not to participate in the labor market at all (extensive margin). The labor market is considered to be non-Walrasian. This is ensured by the presence of the Nash bargaining process, where the firms negotiate the hours worked and wages with the households and divide the surplus generated by the production. The model contains search and matching frictions initially introduced by Mortensen and Pissarides (1994). Also, creating an empty vacancy is costly. Price and wage setting is divided between two types of firms: domestic producers and retailers. The import sector sets the prices of foreign goods and sells 
them on the domestic market. The change of price and wage causes Rotemberg-style adjustment costs, first developed by Rotemberg (1982). The complete model derivation is presented in the article by Albertini et al. (2012). To save space, in this article I present only the log-linear version of the model.

The most important element of the model is the labor market which is defined by the following (log-linearized) equations ${ }^{2}$ :

$$
\begin{array}{lr}
\hat{m}_{t}=v \hat{s}_{t}+(1-v) \hat{v}_{t}+\hat{\varepsilon}_{t}^{\chi}, & N \hat{n}_{t}=\left(1-\rho_{x}\right) N \hat{n}_{t-1}+M \hat{m}_{t}, \\
\hat{s}_{t}=-\left(1-\rho_{x}\right) \frac{N}{S} \hat{n}_{t-1}, & \hat{u}_{t}=-\frac{N}{U} \hat{n}_{t}, \quad \hat{\theta}_{t}=\hat{v}_{t}-\hat{s}_{t},
\end{array}
$$

where $\hat{m}_{t}$ is the matching rate; $v$ is the matching elasticity parameter with respect to the job seekers, $\hat{s}_{t} ; \hat{v}_{t}$ is the vacancy rate and $\hat{\varepsilon}_{t}^{\chi}$ represents the shock to the matching rate. $\hat{n}_{t}$ is the rate of the employed; $\hat{u}_{t}$ stands for the unemployment rate; $\rho_{x}$ is the job separation rate and $\hat{\theta}_{t}$ represents the labor market tightness. The labor market is the place where the unemployed search for vacant job positions and firms seek to fill their vacancies. However, searching for workers and job positions is a costly and time consuming process. Being unemployed or having a vacancy is an unproductive state. Only employees combined with filled vacancies create output. The number of these matches is the result of a Cobb-Douglas matching function. This function gives us the number of vacancy-seeker pairs that are created in each time period. On the other hand, many jobs get destroyed each period at an exogenous and constant job destruction rate. Thus, the number of the employed is expressed by the number of those who keep their job and those who managed to find a new one.

The examined model consists of the foreign sector and three domestic agents: households, firms and monetary authority. Furthermore, there are three types of firms in the model: domestic producers, retailers and foreign goods importers.

A representative household maximizes its expected inter-temporal utility function. This function depends positively on the difference of consumption and the consumption habit, and negatively on the supplied labor. Because there is no capital in the model, the income of the household - wage from work and interests from bonds and assets - are spent solely on the consumption and domestic and foreign bonds. The first order conditions with respect to consumption, $\hat{c}_{t}$, domestic $\left(\hat{d}_{t}\right)$ and foreign $\left(\hat{b}_{t}\right)$ bonds, respectively, have the following forms:

$$
\begin{gathered}
\hat{\lambda}_{t}=\hat{\varepsilon}_{t}^{c}-\frac{1}{1-\vartheta}\left(\hat{c}_{t}-\vartheta \hat{c}_{t-1}\right), \quad \hat{\lambda}_{t}=\hat{r}_{t}+\hat{\lambda}_{t+1}-\hat{\pi}_{t+1}, \\
\hat{b}_{t}-\frac{\hat{b}_{t-1}}{\beta}=\hat{\lambda}_{t}-\hat{c}_{t}-\alpha\left(\widehat{\operatorname{tot}}_{t}+\widehat{\operatorname{lop}}_{t}\right),
\end{gathered}
$$

\footnotetext{
${ }^{2}$ Log-deviations from steady-state follow $\hat{x}_{t}=\log \left(X_{t}\right)-\log (X)$, where $\hat{x}_{t}$ is the log-linearised form of variable $X_{t}$ with steady-state $X$. Variables without the time subscript $t$ represent the steady-state level of the corresponding variable.
} 
with the uncovered interest rate parity (UIP) condition defined as:

$$
\Delta \widehat{r e r}_{t+1}=\hat{r}_{t}-\hat{\pi}_{t+1}-\hat{r}_{t}^{*}+\hat{\pi}_{t+1}^{*}+\tau^{b} \hat{b}_{t}+\hat{\varepsilon}_{t}^{u i p} \text {. }
$$

$\hat{\lambda}_{t}$ is the Lagrange multiplier which represents the shadow value of the budget constraint,; $\hat{\varepsilon}_{t}^{c}$ is the shock to intertemporal preferences; $\vartheta$ is the deep habit parameter of consumption. $\hat{r}_{t}$ and $\hat{r}_{t}^{*}$ represent the domestic and foreign nominal interest rates and $\hat{\pi}_{t}$ and $\hat{\pi}_{t}^{*}$ denote the domestic and foreign inflation rates. $\beta$ is the discount factor and $\alpha$ represents the share of imported goods in the domestic economy; $\tau^{b}$ is the debt elastic risk premium (which means that if domestic households are net borrowers, they are charged a premium) and $\hat{\varepsilon}_{t}^{\text {uip }}$ is the shock to uncovered interest rate parity. $\widehat{t o t}_{t}$ is the terms of trade, $\widehat{\mathscr{O P}}_{t}$ represents the law of one price and $\widehat{\mathrm{rer}}_{t}$ is the real exchange rate. These variables, together with the inflation rates, are defined as follows:

$$
\begin{gathered}
\widehat{\operatorname{rer}}_{t}=\widehat{\operatorname{ner}}_{t}+\hat{p}_{t}^{*}-\hat{p}_{t}, \quad \Delta \widehat{t o t}_{t+1}=\hat{\pi}_{F, t}-\hat{\pi}_{H, t}, \quad \widehat{\operatorname{lop}}_{t}=\widehat{\operatorname{rer}}_{t}-(1-\alpha) \widehat{\operatorname{tot}}_{t}, \\
\hat{\pi}_{t}=(1-\alpha) \hat{\pi}_{H, t}+\alpha \hat{\pi}_{F, t}, \quad \hat{\pi}_{w, t}=\widehat{w}_{t}-\widehat{w}_{t-1}+\hat{\pi}_{t} .
\end{gathered}
$$

The consumption consist of bundles of domestic and foreign goods, which is defined as follows ${ }^{3}$ :

$$
\begin{array}{cc}
\hat{c}_{H, t}=\alpha \eta \widehat{\operatorname{tot}}_{t}+\hat{c}_{t}, & \hat{c}_{H, t}^{*}=\eta\left(\widehat{\operatorname{tot}}_{t}+\widehat{\operatorname{lop}}_{t}\right)+\hat{c}_{t}^{*}, \\
\hat{c}_{F, t}=-\eta(1-\alpha) \widehat{\operatorname{tot}}_{t}+\hat{c}_{t}, & \hat{y}_{t}=(1-\alpha) \hat{c}_{H, t}+\alpha \hat{c}_{H, t}^{*}+\frac{\frac{\kappa^{v}}{e} V^{e}}{Y} e \hat{v}_{t},
\end{array}
$$

where $\eta$ represents the elasticity of substitution between domestic and foreign goods, and $\hat{y}_{t}$ is the domestic output which consists of consumption of domestically produced goods, exports and costs of keeping vacant job positions. $\kappa^{v}$ is a scaling factor and parameter $e$ governs the elasticity of the vacancy posting function.

The decision whether a person works or not depends on the marginal value of a worker for the household, $\hat{\varphi}_{t}$, which is defined as follows:

$$
\begin{aligned}
\varphi \hat{\varphi}_{t}=\Lambda W H\left(\hat{\lambda}_{t}\right. & \left.+\widehat{w}_{t}+\hat{h}_{t}\right)-b_{u} \Lambda \hat{\lambda}_{t}-\kappa^{h} \frac{H^{1+\phi_{h}}}{1+\phi_{h}}\left(\hat{\varepsilon}_{t}^{c}+\kappa_{t}^{h}+\left(1+\phi_{h}\right) \hat{h}_{t}\right) \\
& +\beta\left(1-\rho_{x}\right) \varphi\left(\hat{\varphi}_{t+1}\left(1-\frac{M}{S}\right)-\frac{M}{S}\left(\widehat{m}_{t+1}-\hat{s}_{t+1}\right)\right)
\end{aligned}
$$

The domestic intermediate goods producers are the only type of firm that hires workers and sets their wages. Such firms maximize their inter-temporal profit function, while facing hiring and quadratic wage adjustment costs as in Rotemberg's study (1982). Due

\footnotetext{
${ }^{3}$ Note that subscripts represent the place of origin: $H$ is the domestic economy, $F$ is the foreign sector. Furthermore, variables with asterisk are applied in the foreign economy: for example, $\hat{c}_{H, t}^{*}$ stands for foreign consumption of home produced goods (exports).
} 
to the absence of capital, the production function with the labor share in production, $\zeta$, is defined as:

$$
\hat{y}_{t}=\hat{\varepsilon}_{t}^{a}+\zeta\left(\hat{h}_{t}+\hat{n}_{t}\right)
$$

Similar to the marginal value of a worker to the household, the marginal value of a job is defined for the producer as:

$$
\begin{gathered}
\mu \hat{\mu}_{t}=M C \zeta \frac{Y}{N}\left(\widehat{m c}_{t}+\hat{y}_{t}-\hat{n}_{t}\right)-W H\left(\widehat{w}_{t}+\hat{h}_{t}+\alpha \widehat{t o t}_{t}\right) \\
+\beta\left(1-\rho_{x}\right) \mu\left(\hat{\lambda}_{t+1}-\hat{\lambda}_{t}+\hat{\mu}_{t+1}\right)
\end{gathered}
$$

and the job creation condition is expressed as:

$$
\hat{\mu}_{t}=(e-1) \hat{v}_{t}-\left(\hat{m}_{t}-\hat{v}_{t}\right)
$$

where $e$ represents the elasticity of vacancy creation and $\left(\widehat{m}_{t}-\hat{v}_{t}\right)$ is the probability of finding a new worker. The goods producers negotiate the wages and the hours worked through the Nash bargaining process, $\left(\varphi_{t} / \Lambda_{t}\right)^{1-\xi_{t}} \mu_{t}^{\xi_{t}}$, with a time varying negotiating power of firms, $\xi_{t}$. Deriving the first order condition with respect to wages results in:

$$
\begin{gathered}
\hat{\mu}_{t}+\hat{h}_{t}=\hat{\varphi}_{t}-\hat{\lambda}_{t}+\hat{\mu}_{t}^{\prime w}-\frac{\xi_{t}}{1-\xi} \\
\hat{\mu}_{t}^{\prime w}=\hat{h}_{t}+\alpha \widehat{t o t}_{t}+\frac{\psi_{W} Y}{W}+\hat{\pi}_{w, t}-\gamma_{W} \hat{\pi}_{w, t-1}-\left(\hat{\pi}_{w, t+1}-\gamma_{W} \hat{\pi}_{w, t}\right),
\end{gathered}
$$

where $\psi_{W}$ is the parameter defining the wage rigidity and $\gamma_{W}$ is the wage indexation parameter to past inflation. The FOC with respect to hours worked is derived analogously. The producers sell their unfinished goods on a perfectly competitive market to the second type of firm: the domestic retailers. The result of their decision making is the New Keynesian Phillips Curve (NKPC):

$$
\hat{\pi}_{H, t}=\frac{\beta}{1+\beta \gamma_{H}} \hat{\pi}_{H, t+1}+\frac{\gamma_{H}}{1+\beta \gamma_{H}} \hat{\pi}_{H, t-1}+\frac{(\epsilon-1) \widehat{m c}_{t}}{\left(1+\beta \gamma_{H}\right) \psi_{H}}-\frac{\hat{\varepsilon}_{t}^{H}}{\left(1+\beta \gamma_{H}\right) \psi_{H}} .
$$

The retailers combine the differentiated intermediate goods into final goods and sell it to the representative household on a monopolistically competitive market. This gives them the opportunity to adjust their prices. However, each price change induces an increase of costs because of the Rotemberg-type price adjustment cost which is governed by the parameter $\psi_{H} . \hat{\varepsilon}_{t}^{H}$ represents the cost-push shock. The retailers have to choose whether to change their prices despite the increased costs or keep them at their former levels. The importers, the final type of firm, function similarly to the retailers and have similar NKPC. They import goods and set their domestic prices at a monopolistically competitive market. The importers face price adjustment costs and fluctuations of the exchange rate.

The final agent in the model is the monetary authority which is modelled using a Taylor rule. As described by Albertini et al. (2012), the central bank sets the current nominal interest rate based on its previous value, the deviation of inflation from its target, the 
output from its steady state, and the differences of output and exchange rate from their previous values:

$$
\begin{gathered}
\hat{r}_{t}=\left(1-s w_{t}\right)\left(\rho_{r} \hat{r}_{t-1}+\left(1-\rho_{r}\right)\left(\rho_{\pi} \hat{\pi}_{t+1}+\rho_{y} \hat{y}_{t}+\rho_{\Delta y} \Delta \hat{y}_{t}\right.\right. \\
\left.\left.+\rho_{\Delta \mathrm{ner}} \Delta \widehat{n e r}_{t}\right)+\hat{\varepsilon}_{t}^{m}\right)+s w_{t} \hat{r}_{t}^{*}
\end{gathered}
$$

where $\rho_{r}$ is the interest rate smoothing parameter, $\rho_{\pi}, \rho_{y}, \rho_{\Delta y}, \rho_{\Delta \text { ner }}$ are policy coefficients and $\hat{\varepsilon}_{t}^{m}$ is the monetary policy shock. $s w_{t}$ is a switching variable which is 0 in the periods between 2002-Q1 and 2008-Q4, and 1 since 2009-Q1. Since Slovakia entered the euro area and gave up its autonomous monetary policy in 2009, it is necessary to implement a switching mechanism. The switch changes the Taylor rule in the period after 2009 to $\hat{r}_{t}=\hat{r}_{t}^{*}$, which in turn results in the following UIP condition:

$$
\Delta \widehat{r e r}_{t}=\hat{\pi}_{t}^{*}-\hat{\pi}_{t}+\tau^{b} \hat{b}_{t}+\hat{\varepsilon}_{t}^{u i p}
$$

I have also estimated the model with a simplified Taylor rule, as described below in the section Model modifications, which resulted in a decrease of the quality of results. The inclusion of nominal exchange rate to the decision making rule of the monetary authority before 2009 is also considered due to the transition from an autonomous currency to the common currency of the euro area, which greatly influenced the monetary policy.

The foreign sector is represented by three equations for output, inflation and interest rate analogous to the domestic economy:

$$
\begin{gathered}
\hat{y}_{t}^{*}-\vartheta^{*} \hat{y}_{t-1}^{*}=\hat{y}_{t+1}^{*}-\vartheta^{*} \hat{y}_{t}^{*}-\left(1-\vartheta^{*}\right)\left(\hat{r}_{t}^{*}-\hat{\pi}_{t+1}^{*}\right)+\left(1-\vartheta^{*}\right)\left(\hat{\varepsilon}_{t}^{y^{*}}-\hat{\varepsilon}_{t+1}^{y^{*}}\right), \\
\hat{r}_{t}^{*}=\rho_{r^{*}} \hat{r}_{t-1}^{*}+\left(1-\rho_{r^{*}}\right)\left(\rho_{\pi^{*}} \hat{\pi}_{t+1}^{*}+\rho_{y^{*}} \hat{y}_{t}^{*}+\rho_{\Delta y^{*}} \Delta \hat{y}_{t}^{*}\right)+\hat{\varepsilon}_{t}^{m^{*}}, \\
\hat{\pi}_{t}^{*}=\frac{\beta}{1+\beta \gamma^{*}} \hat{\pi}_{t+1}^{*}+\frac{\gamma^{*}}{1+\beta \gamma^{*}} \hat{\pi}_{t-1}^{*}+\frac{(\epsilon-1) \kappa^{y^{*}} \hat{y}_{t}^{*}}{\left(1+\beta \gamma^{*}\right) \psi^{*}}-\frac{\hat{\varepsilon}_{t}^{\pi^{*}}}{\left(1+\beta \gamma^{*}\right) \psi^{*}} .
\end{gathered}
$$

To investigate the degree of frictions in the Slovak economy, I have estimated this model. The flexibility of the labor market is evaluated based on the estimated values of the rigidity parameters. The labor market rigidities in the model can be summarized as follows:

- $\quad$ wage adjustment costs - represent additional expenses when a firm renegotiates the workers' wages;

- matching frictions - stand for the effectiveness of the matching process from the jobseeker's point of view;

- hiring costs - signalize whether the cost of hiring additional employees is increasing, and is therefore demotivating the firms; and

- bargaining processes - define the strength of negotiation of firms and households in the hours and wage setting mechanism.

\section{Model modifications}

First I estimated the model described in the paper by Albertini et al. (2012), which served as a baseline model. Then I made several modifications to this model and used 
Bayesian model comparison methods, like the Bayes factor, to examine which modifications improved the achieved results. The Bayes factor compares the marginal densities of estimations and prefers the model with a higher density. For example, I learned that simplifying the Taylor rule in equation (12) by removing the dependence of interest rate, $\hat{r}_{t}$, on the exchange rate, $\Delta \widehat{n e r}_{t}$, and output gap, $\hat{y}_{t}$, leads to the decrease of marginal density.

The model described in this section contains two modifications leading to the increase of the marginal density, and, therefore, this model is preferred over the baseline model. These modifications include the implementation of a monetary regime switch to capture the country's entry to the euro area and surrendering its autonomous monetary policy to the European Central Bank. I use a similar regime switch to the one implemented by Senaj et al. (2010) or Tvrz and Vašíček (2016). The insertion of such a regime switch reflects that the switch is $(i)$ permanent, (ii) unexpected and (iii) the threshold is known exactly. The regime switch, $s w_{t}$, is present in equation (12) which represents the domestic monetary authority's decision making rule. Furthermore, in line with Múčka and Horváth's findings (2015), I extend the simple AR (1) foreign sector with a more complex definition to capture the interactions between the foreign variables. I have implemented a simple three-equation foreign sector, determined by equations (14) - (16), that defines the behavior of the three foreign agents. This approach indicates that the domestic and foreign agents behave in accordance with the same principles. The foreign households maximize their utility based on the same function as the domestic households do (equation (14)). The firms maximize their profits and set the output prices following the Rotemberg price setting principle (eq. (16)). The monetary authority sets the nominal interest rate in accordance with the Taylor rule (eq. (15)). Since the foreign sector is much larger than the domestic one, it is not affected by the small open economy.

\section{Data and parameter calibration}

Following Albertini et al. (2012), 8 time series (gross domestic product, interest rate, inflation, exchange rate, unemployment, vacancies, wage and hours worked) are selected for the domestic economy and 3 time series (gross domestic product, interest rate and inflation) for the foreign sector, which is represented by the 19 countries of the euro area. This group of countries gathers the main trading partners of Slovakia. Although Slovakia is a part of this foreign sector, its impact on the overall performance of the euro area is negligible. The GDP of Slovakia is around $0.5 \%$ of the total output of the euro area countries.

Each of the time series has been acquired from the database of the National Bank of Slovakia (NBS) ${ }^{4}$, with the exception of the nominal exchange rate which has been obtained from the database of the European Central Bank. The domestic output per capita is defined as the real gross domestic product measured using the expenditure method

\footnotetext{
${ }^{4}$ Available from: http://www.nbs.sk/en/monetary-policy/macroeconomicdatabase/macroeconomic-database-chart.
} 
divided by the economically active population. The nominal interest rate is represented by the three-month EURIBOR interest rate that came into effect in 2009. Until then, the BRIBOR had been used for the Slovak economy. The differences in logarithms of the Harmonized Index of Consumer Prices (HICP) denote the domestic inflation. The harmonized index is used to ensure the comparability and compatibility between the domestic and foreign sector. The nominal exchange rate is represented by the actual exchange rate used until 2008. The constant exchange rate of 30.126 is used for the following years to represent the fixation of the Slovak koruna to the euro. The real exchange rate is then calculated as the nominal rate adjusted with the inflation differential. The unemployment rate is taken from the Labor Force Survey which was provided to the NBS by the Statistical Office of the Slovak Republic. The real wages are represented by hourly wages denoted in the euro as defined by the European system of national and regional accounts divided by the HICP inflation rate. The vacancy rate is calculated as the number of vacancies published by the Central Office of Labor, Social affairs and Family (which is also available from the NBS's database) divided by the active labor force. The hours are represented as the average quarterly hours worked of one employee acquired from the NBS calculations of the data of Statistical Office of the Slovak Republic.

The foreign output is represented by the real gross domestic product of the euro area. The inflation rate is calculated analogously to the domestic inflation from the HICP of the euro area. The nominal interest rate is captured by the three-month interbank interest rate (EURIBOR).

Quarterly data sets of the observed variables are obtained for the time between the first quarter of 2002 to the fourth quarter of 2016. The first and the last observation are defined by the availability of the data. To be able to search for potential structural or dynamical changes and to investigate the long-term effects of the crisis, I have decided to split the examined time period at the time of the recession in 2009. As the National Bureau of Economic Research (NBER) typically dates the start of a recession by the first quarter in which the economy undergoes two quarters of negative growth, it seems reasonable to divide the observed time period here. The second significant drop in output occurred in the first quarter of 2009, and thus this observation is the first one in the after-crisis period. Hence, the Great Recession of 2009 divides the observation period into two parts of similar length. This increases the value of the comparison of data evolution before and after (or during - I use both of these terms to represent the time period after 2009) the crisis. The pre-crisis period spans from 2002-Q1 to 2008-Q4, which counts 28 observations, and the post-crisis period covers observations from between the years 2009-Q1 and 2016-Q4, which counts 32 observations. Such a division is also in line with the change of monetary regime in the Slovak economy from an autonomous monetary policy to a joint regime with the European Central Bank.

Each of the time series has been obtained in a seasonally unadjusted form, so the same type of a seasonal adjustment can be performed on all of the observed variables. The time series, except the interest rates, are logarithmized to match the data with the loglinear representation of the model. To remove the trend and stationarize the time series, the Hodrick and Prescott (1980) filter is used with the standard smoothing parameter, $\lambda$ $=1600$ for quarterly data. 
Figure 2 Model's input data
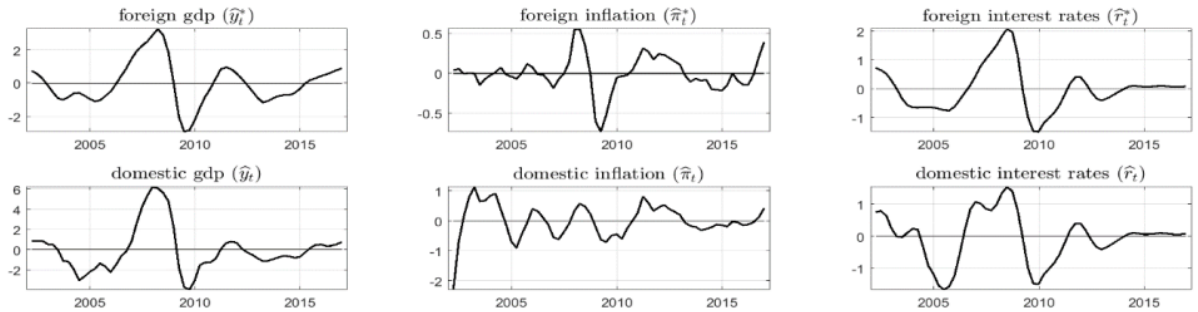

domestic interest rates $\left(\widehat{r}_{t}\right)$
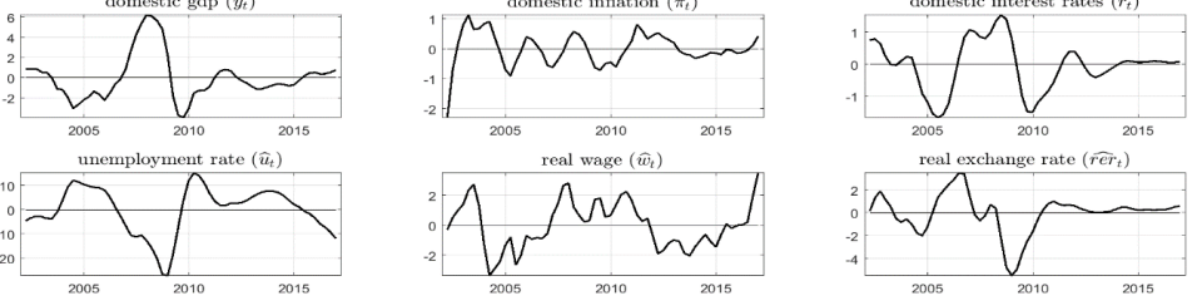

real exchange rate $\left(\widehat{\operatorname{rer}}_{t}\right)$
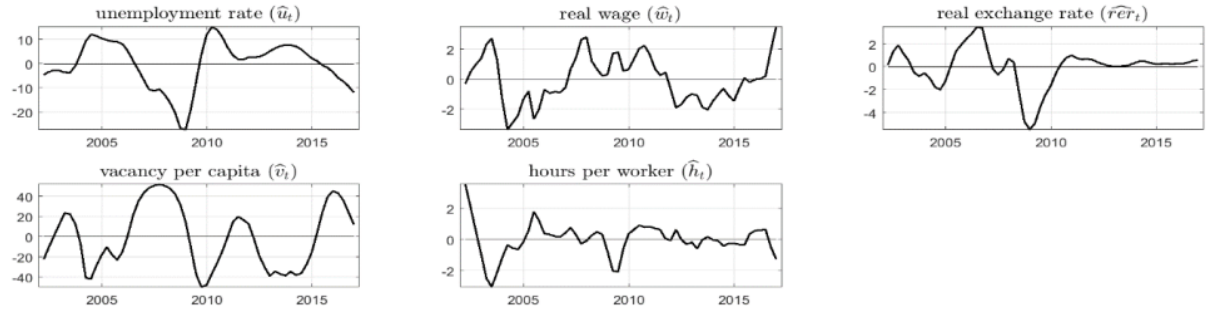

Source: National Bank of Slovakia, authors' computations.

Figure 2 captures the 11 time series observed, after seasonal adjustment and stationarization, which enter the model. The HP filter ensures that the data oscillate around zero mean.

\section{Calibration}

Before the model is estimated, it is necessary to calibrate the parameters to pin down the steady state of the model and to compel the model to correspond with the long-run properties of the economy.

Table 1 Fixed parameter setting

\begin{tabular}{clc|clc}
\hline & Name & Value & & Name & Value \\
\hline$\beta$ & discount factor & 0.99 & $\zeta$ & share of labor in production & $2 / 3$ \\
$\epsilon$ & elasticity of substitution & 6 & $\tau^{b}$ & el. of debt elastic risk premium & 0.001 \\
\hline$U$ & steady state of unemployment & 0.1377 & $\chi$ & efficiency of matching & 0.3289 \\
$\kappa^{v}$ & scaling factor to vacancy posting & 0.2454 & $\rho_{x}$ & exogenous job separation rate & 0.02 \\
$\alpha$ & import share on GDP & 0.4431 & $\kappa^{h}$ & scaling factor to dis-utility of work & 7.8094 \\
\hline
\end{tabular}

Source: The values of the first four parameters are taken from other articles. The rest is calculated from the data by the authors.

Table 1 contains the values of fixed parameters. The discount factor, labor share in production and parameter of risk premium are obtained from other articles dealing with similar models and economies, like those by Jakab and Kónya (2016) or Němec (2013). I imitate Senaj et al. (2010) and Ireland (2007) in the setting of the elasticity of substitu- 
tion between differentiated goods, $\epsilon$, to 6 , which corresponds to the price adjustment cost parameter values defined below. The remaining calibrated parameters are calculated from the data or the steady state relations between variables.

Table 2 contains the list of the estimated parameters. The prior distributions are set in line with the original article by Albertini et al. (2012) with relatively high standard deviations. A similar setting can be found in works of other authors, like Tvrz and Vašíček (2016) or Keen and Wang (2007), who derive the price adjustment cost parameter from the Calvo (1983) type price setting with a steady-state markup $1.2(\epsilon=6)$ and price reoptimization intervals of 4 quarters to 58.25.

Table 2 Prior distributions of estimated parameters

\begin{tabular}{clccc} 
Parameter & Name & Distribution & Mean & Std. dev. \\
\hline$\vartheta, \vartheta^{*}$ & habit & beta & 0.5 & 0.15 \\
$\phi_{h}$ & inverse of Frisch elasticity & gamma & 1 & 0.2 \\
$\eta$ & elasticity of substitution (dom. \& for. goods) & gamma & 1 & 0.2 \\
$\xi$ & bargaining power of firms & beta & 0.5 & 0.2 \\
$v$ & elasticity of matching & beta & 0.5 & 0.2 \\
$e$ & elasticity of vacancy creation cost & gamma & 1 & 0.5 \\
\hline$\gamma_{H}, \gamma_{F}, \gamma_{w}, \gamma^{*}$ & backward looking price/wage indexation & beta & 0.75 & 0.1 \\
$\psi_{H}, \psi_{F}, \psi_{w}, \psi^{*}$ & price/wage adjustment cost & gamma & 50 & 15 \\
$\kappa^{y^{*}}$ & foreign marginal cost scaling factor & gamma & 0.1 & 0.5 \\
\hline$\rho_{r}, \rho_{r^{*}}$ & interest rate smoothing & beta & 0.5 & 0.15 \\
$\rho_{\pi}, \rho_{\pi^{*}}$ & inflation & gamma & 1.5 & 0.25 \\
$\rho_{y}, \rho_{y^{*}}$ & output gap & normal & 0.25 & 0.1 \\
$\rho_{\Delta y}, \rho_{\Delta y^{*}}$ & difference of output & normal & 0.25 & 0.1 \\
$\rho_{\Delta \text { ner }}$ & difference of exchange rate & normal & 0.25 & 0.1 \\
\hline
\end{tabular}

Source: Prior setting based on existing literature.

\section{Estimation methods}

The above model can be expressed in a system of rational expectations. This system is defined in a form in which agents make use of all the information available at the time $t$ when they are creating their expectations. In these systems, a distinction between two kinds of variables is made: predetermined and non-predetermined (forward looking). A predetermined variable is only defined by the variables known at the time $t$; whereas a non-predetermined variable can also be a function of variables from $t+1$.

I use the Bayesian approach to solve the model. Griffoli (2010) points out five reasons why it is more advantageous to use the Bayesian methods to estimate a DSGE model. Firstly, if the model is well-specified, the Bayesian estimation fits the complete, solved DSGE model, as opposed to the generalized method of moments estimation which is based on particular equilibrium relationships. Secondly, the pres- 
ence of priors in the Bayesian methods can tilt the peak of the posterior distribution from values that are contradictory to common observations even if the likelihood peaks there. Thirdly, the prior setting also helps with the problem of parameter identification. It can be helpful by adding enough information to the posterior distribution to allow numerical maximization. Fourthly, the Bayesian estimation addresses the problem of model misspecification by including shocks in the structural equations, which can be interpreted as observation errors. Lastly, the Bayesian estimation allows an easy comparison of models. By a comparison of the posterior distributions of different models with the data, the best fitting model can be discovered.

To examine the unobservable state of a variable, such as the labor market tightness, the Kalman (1960) filter is used. The estimations are carried out in Matlab R2016a with Dynare version 4.4.3. For each estimation two chains of Random-Walk Metropolis-Hastings algorithm are generated. Each chain contains 600.000 draws of which the initial $66 \%$ is dropped as a burn-in. I assess the acceptance ratio to be around 0.35 .

\section{Results of estimation}

To check whether the model provides an accurate representation of the real economy, I have examined the simulated moments. Given the labor market orientation of this paper,

Table 3 Simulated and actual moments - standard deviations and cross-correlations

\begin{tabular}{cllccccc} 
& & & \multicolumn{6}{c}{ Cross-correlation } \\
\cline { 4 - 8 } Variable & & Std. dev. & $\hat{y}_{t}$ & $\hat{h}_{t}$ & $\hat{u}_{t}$ & $\widehat{w}_{t}$ & $\hat{v}_{t}$ \\
\hline \multirow{2}{*}{$\hat{y}_{t}$} & data & 0.022 & 1.000 & 0.153 & -0.848 & 0.408 & 0.763 \\
& model & 0.029 & 1.000 & 0.845 & -0.283 & -0.231 & 0.215 \\
\hline \multirow{2}{*}{$\hat{h}_{t}$} & data & 0.010 & 0.153 & 1.000 & -0.002 & -0.260 & 0.007 \\
& model & 0.039 & 0.845 & 1.000 & 0.154 & -0.131 & 0.016 \\
\hline \multirow{2}{*}{$\hat{u}_{t}$} & data & 0.099 & -0.848 & -0.002 & 1.000 & -0.392 & -0.745 \\
& model & 0.102 & -0.283 & 0.154 & 1.000 & 0.212 & -0.220 \\
\hline \multirow{2}{*}{$\hat{w}_{t}$} & data & 0.016 & 0.408 & -0.260 & -0.392 & 1.000 & 0.464 \\
& model & 0.035 & -0.231 & -0.131 & 0.212 & 1.000 & -0.191 \\
\hline \multirow{2}{*}{$\hat{v}_{t}$} & data & 0.309 & 0.763 & 0.007 & -0.745 & 0.464 & 1.000 \\
& model & 0.405 & 0.215 & 0.016 & -0.220 & -0.191 & 1.000 \\
\hline
\end{tabular}

Source: Data from the NBS database, authors' computations.

Table 3 contains the standard deviations and cross-correlations of output and labor market variables. The simulations show that the model is able to capture the standard deviations of output, unemployment and vacancies relatively well. However, it generates much higher volatilities for hours worked and wages. This could be explained by the fact that the model connects the volatility of productivity with the 
dynamics of hours worked, and therefore assumes much higher fluctuations in hours worked than can actually be observed in the data. This can also be seen in the correlation of hours worked with output, where the model reports a correlation more than five times stronger. On the other hand, the correlation between unemployment and output is comparably weaker. Nonetheless, the model is able to capture both the negative relation between $\hat{y}_{t}$ and $\hat{u}_{t}$ (Okun's law) as well as the negative relation between $\hat{v}_{t}$ and $\hat{u}_{t}$ (Beveridge curve). The correlation between wages and other observed variables is at odds with the data. Similar results can be found in studies by Němec (2013) or Lubik (2009) who explain it to be the result of a matching shock's presence which can act as a residual in employment and wage equations.

Table 4 contains the results of the in-sample simulations. Root mean square errors (RMSE) are calculated for the DSGE model presented above and for a simple vector autoregressive (VAR) model of order 1. The RMSEs are presented for one and four quarters ahead forecast. The results indicate that the DSGE model outperforms the VAR model in the prediction of the output, unemployment and wages. It is slightly worse in the short-run prediction of hours worked; however, it predicts a somewhat better outcome in the long term. The VAR model gives more positive results regarding the vacancy rate of Slovakia; although it is important to note that these differences are not significant. Overall, my results confirm that DSGE models are more suitable for longterm predictions.

Table 4 Root mean square errors of the DSGE model and a VAR(1) model

\begin{tabular}{cccc} 
Variable & RMSE & DSGE & VAR(1) \\
\hline \multirow{2}{*}{$\hat{y}_{t}$} & 1 period & $\mathbf{0 . 0 0 5}$ & 0.009 \\
& 4 periods & $\mathbf{0 . 0 1 6}$ & 0.050 \\
\hline \multirow{2}{*}{$\hat{h}_{t}$} & 1 period & 0.009 & $\mathbf{0 . 0 0 5}$ \\
& 4 periods & $\mathbf{0 . 0 1 6}$ & 0.017 \\
\hline \multirow{2}{*}{$\hat{u}_{t}$} & 1 period & $\mathbf{0 . 0 2 3}$ & 0.037 \\
& 4 periods & $\mathbf{0 . 1 1 8}$ & 0.187 \\
\hline \multirow{2}{*}{$\widehat{w}_{t}$} & 1 period & $\mathbf{0 . 0 0 7}$ & 0.010 \\
& 4 periods & $\mathbf{0 . 0 2 0}$ & 0.039 \\
\hline \multirow{2}{*}{$\hat{v}_{t}$} & 1 period & 0.145 & $\mathbf{0 . 0 9 3}$ \\
& 4 periods & 0.411 & $\mathbf{0 . 4 0 5}$
\end{tabular}

Source: Authors' computations. Note: values written with bold font in the RMSE comparison of DSGE and VAR models represent lower RMSE means.

I simulate predictions for four periods ahead, which is one year for quarterly data. The first three years and the last year are left out of the simulation to minimize the effect of end of sample bias of the HP filter, while the forecasting horizon is set to four quarters ahead. I decided not to simulate the foreign variables because the model only provides limited information about their development. Figure 3 depicts the results of in-sample simulations of the DSGE model. The black thick lines represent the observed data and the thin lines are the means of the simulated forecasts. 
The RMSEs for one period ahead are presented in the boxes for each observed time series.

Figure 3 Conditional forecast efficiency cascades with simulated unexpected shocks
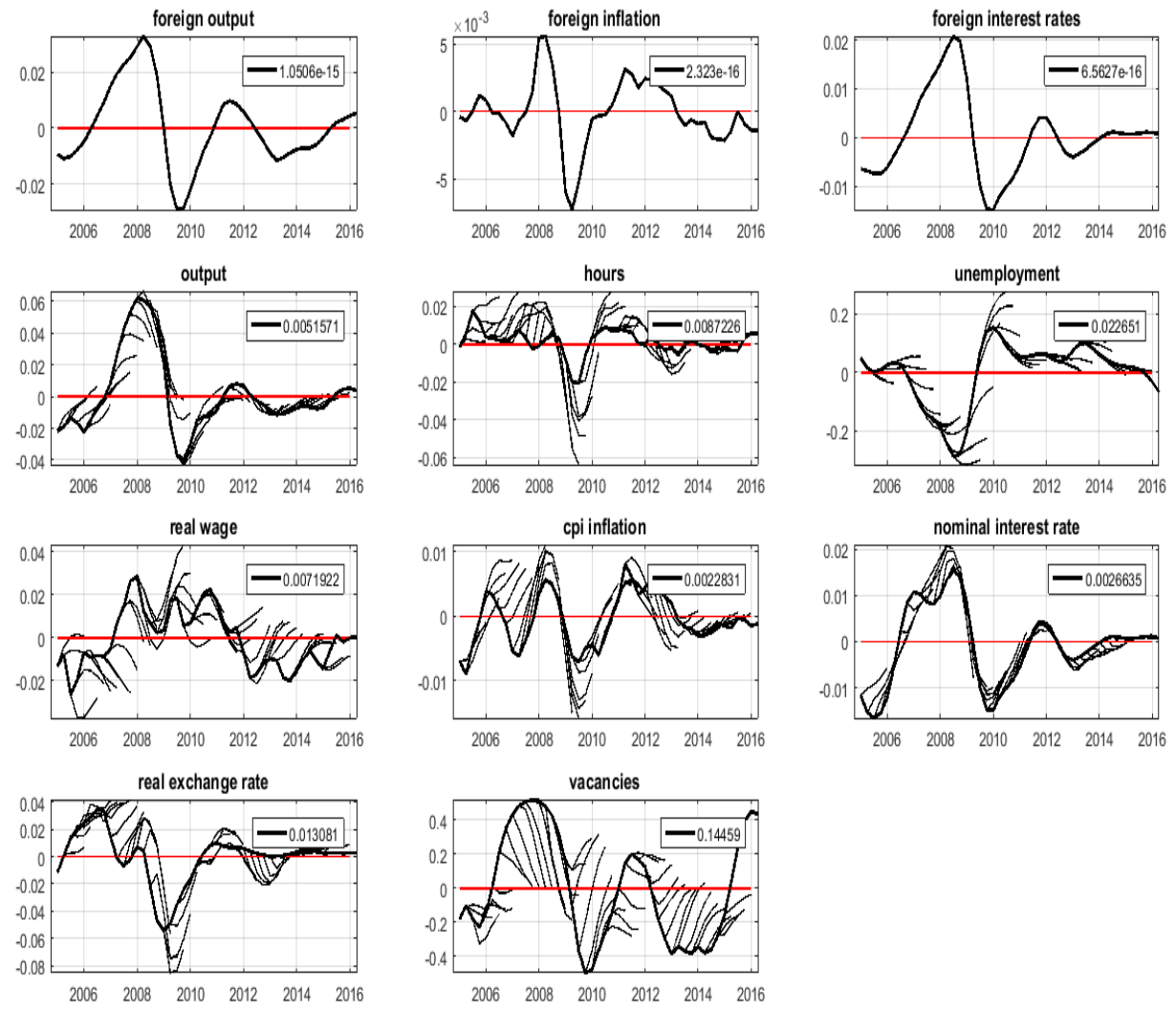

Source: Authors' computations.

Figure 4 demonstrates the multivariate convergence diagnostic of the estimation. As Pfeifer (2017) points out, the Interval shows the Brooks and Gelman (1998) convergence diagnostics for the $80 \%$ interval. The blue line (in my case starting higher in each box) shows the $80 \%$ quantile range based on the pooled draws from all sequences, while the red line (in my case starting lower in each box) shows the mean interval range based on the draws of the individual sequences. $m 2$ and $m 3$ show an estimate of the same statistics, which is based on the range of the posterior likelihood function (the posterior kernel is used to aggregate the parameters), for the second and third central moments, i.e. the squared and cubed absolute deviations from the pooled and the within-sample mean, respectively. The achieved convergence is indicated by the two lines stabilizing and staying close to each other. 
Figure 4 Multivariate convergence diagnostics for the Metropolis-Hastings
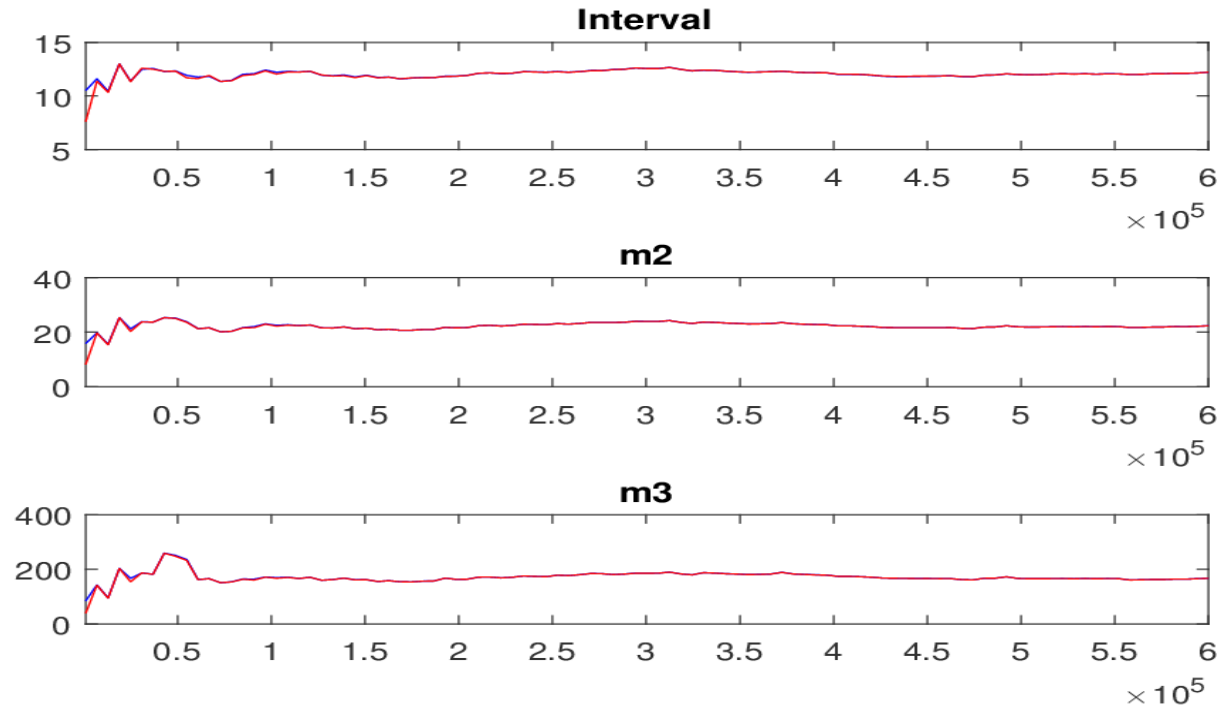

Source: Authors' computations.

\section{Structural characteristics}

The results of parameter estimates are presented in Table 5. Three estimations are executed: one using the full sample (which will be also used below in the examination of historical development), one on the data before the crisis, and one with the data from 2009. The latter two are used to compare and evaluate the differences between the two time periods - resulting from either the Great Recession or the entry of Slovakia to the euro area. First, I estimate the model for the full sample using the parameters calibrated in the previous section. The same values are used for the estimation of the first part of the observed time period. Following Jakab and Kónya (2016), I then use the posterior estimates as a prior setting for the estimation of the second sub-sample. The Taylor-rule parameters are not estimated in this period as the NBS gave up its power to intervene in the flows of the Slovak economy in favor of the ECB.

The first difference between the two shorter estimates is related to the increase of consumption habit of households, $\vartheta$, from 0.67 to 0.8 . This change of habit signalizes a decrease in the flexibility of consumption, which can be explained by the increase of the households' need to smooth the consumption in times of a recession. In their simulation, Senaj et al. (2010) calibrate this parameter to 0.64, which is close to my estimate for the period before the crisis. The domestic and foreign goods elasticity parameter, $\eta=0.81$ for both periods, reports a willingness to replace domestically produced goods by imported products. This is in line with the great degree of openness of Slovak economy and its dependence on imports. Similar value can be found, for example, in a paper by Bergholt (2015) who investigated the influence of foreign shocks on the Canadian economy. 
The reaction of matches with respect to any changes in the job seekers rate, $v$, is lower than the values common in the literature, such as studies by Němec (2013) or Christoffel et al. (2009) who estimate this parameter to be around 0.8. However, my estimates also tilt this parameter in favor of unemployment in both shorter periods $(v>0.5)$. The model reports relatively low values of firms' bargaining power, $\xi$, compared to the estimates by Němec (2013) for Slovakia and the Czech Republic or Jakab and Kónya (2016) for Hungary who report this parameter to be close to 1 . Furthermore, even though the elasticity of vacancy creation, $e$, is significantly higher than 1, implying increasing hiring costs (contrary to the original paper by Rotemberg (2008), who assigned this parameter a value far below 1), it is noticeably lower than values estimated by Němec (2013) (2.3) or Albertini et al. (2012) (5.22). This lower value, compared to the other articles, compensates for the lower bargaining power of firms allowing producers to create new jobs for lower, although still increasing, costs. Higher values of this parameter indicate less flexible labor markets.

The price and wage indexation parameters $\left(\gamma_{H}, \gamma_{F}\right.$ and $\left.\gamma_{W}\right)$ remain close to their prior means. The same holds for the wage adjustment cost $\left(\psi_{w}\right)$ for the estimation before 2009. On the other hand, the price adjustment costs of domestic $\left(\psi_{H}\right)$ and foreign $\left(\psi_{F}\right)$ goods shifts downwards from their respective prior means. Nonetheless, the adjustment costs of domestic prices and workers' wages increases significantly in the period after the crisis. This increase of wage stickiness reflects the long post-crisis period when the real wage had remained rigid for significantly long time. The same can be observed in the case of domestic prices in the last few years. Even though the price adjustment cost of foreign goods in the foreign economy $\left(\psi^{*}\right)$ increased slightly after the recession, this rise is not reflected in the increase of imported goods' price adjustment cost. This can mainly be contributed to the adoption of the euro which reduced the transaction costs of foreign goods connected to the exchange rate.

\section{Table 5 Estimated parameters}

\begin{tabular}{|c|c|c|c|c|}
\hline Parameter & Name & $\begin{array}{c}\text { Complete } \\
\text { 2002Q1-2016Q4 }\end{array}$ & $\begin{array}{c}\text { Before } \\
\text { 2002Q1-2008Q4 }\end{array}$ & $\begin{array}{c}\text { After/During } \\
\text { 2009Q1-2016Q4 }\end{array}$ \\
\hline$\vartheta$ & habit & $\begin{array}{c}0.727 \\
(0.641-0.817)\end{array}$ & $\begin{array}{c}0.674 \\
(0.542-0.811)\end{array}$ & $\begin{array}{c}0.801 \\
(0.745-0.862)\end{array}$ \\
\hline$\phi_{h}$ & inverse of Frisch elasticity & $\begin{array}{c}0.947 \\
(0.658-1.235)\end{array}$ & $\begin{array}{c}0.993 \\
(0.684-1.290)\end{array}$ & $\begin{array}{c}0.998 \\
(0.715-1.277)\end{array}$ \\
\hline$\eta$ & $\begin{array}{l}\text { elasticity of substitution (dom. } \\
\& \text { for. goods) }\end{array}$ & $\begin{array}{c}0.834 \\
(0.625-1.037) \\
\end{array}$ & $\begin{array}{c}0.812 \\
(0.594-1.026) \\
\end{array}$ & $\begin{array}{c}0.811 \\
(0.621-1.001) \\
\end{array}$ \\
\hline$\xi$ & bargaining power of firms & $\begin{array}{c}0.297 \\
(0.085-0.498)\end{array}$ & $\begin{array}{c}0.389 \\
(0.155-0.620)\end{array}$ & $\begin{array}{c}0.329 \\
(0.187-0.472)\end{array}$ \\
\hline$v$ & elasticity of matching & $\begin{array}{c}0.478 \\
(0.240-0.709)\end{array}$ & $\begin{array}{c}0.561 \\
(0.320-0.803)\end{array}$ & $\begin{array}{c}0.593 \\
(0.374-0.813)\end{array}$ \\
\hline$e$ & $\begin{array}{l}\text { elasticity of vacancy creation } \\
\text { cost }\end{array}$ & $\begin{array}{c}1.650 \\
(1.376-1.932)\end{array}$ & $\begin{array}{c}1.541 \\
(1.279-1.815)\end{array}$ & $\begin{array}{c}1.610 \\
(1.453-1.764)\end{array}$ \\
\hline$\gamma_{H}$ & $\begin{array}{l}\text { backward looking price (dom. } \\
\text { goods) }\end{array}$ & $\begin{array}{c}0.788 \\
(0.660-0.927)\end{array}$ & $\begin{array}{c}0.775 \\
(0.640-0.926)\end{array}$ & $\begin{array}{c}0.783 \\
(0.651-0.921)\end{array}$ \\
\hline$\gamma_{F}$ & backward looking price (for. & 0.769 & 0.751 & 0.771 \\
\hline
\end{tabular}




\begin{tabular}{|c|c|c|c|c|}
\hline & goods) & $(0.627-0.913)$ & $(0.602-0.905)$ & $(0.624-0.926)$ \\
\hline$\gamma_{W}$ & $\begin{array}{l}\text { backward looking wage } \\
\text { parameter }\end{array}$ & $\begin{array}{c}0.690 \\
(0.525-0.853)\end{array}$ & $\begin{array}{c}0.717 \\
(0.553-0.888)\end{array}$ & $\begin{array}{c}0.724 \\
(0.569-0.887)\end{array}$ \\
\hline$\psi_{H}$ & price adj. cost (dom. goods) & $\begin{array}{c}47.916 \\
(28.808-66.541)\end{array}$ & $\begin{array}{c}41.568 \\
(23.181-59.351)\end{array}$ & $\begin{array}{c}60.885 \\
(44.953-77.149)\end{array}$ \\
\hline$\psi_{F}$ & price adj. cost (for. goods) & $\begin{array}{c}38.273 \\
(19.438-56.103)\end{array}$ & $\begin{array}{c}43.144 \\
(20.629-64.684)\end{array}$ & $\begin{array}{c}41.749 \\
(22.705-60.815)\end{array}$ \\
\hline$\psi_{W}$ & wage adj. cost & $\begin{array}{c}57.068 \\
(35.943-77.869)\end{array}$ & $\begin{array}{c}49.811 \\
(29.156-70.680)\end{array}$ & $\begin{array}{c}61.245 \\
(43.314-79.014) \\
\end{array}$ \\
\hline$\rho_{r}$ & interest rate smoothing & $\begin{array}{c}0.767 \\
(0.725-0.810)\end{array}$ & $\begin{array}{c}0.748 \\
(0.672-0.826)\end{array}$ & - \\
\hline$\rho_{\pi}$ & inflation & $\begin{array}{c}1.514 \\
(1.353-1.675)\end{array}$ & $\begin{array}{c}1.510 \\
(1.343-1.673)\end{array}$ & $(-)$ \\
\hline$\rho_{y}$ & output gap & $\begin{array}{c}0.270 \\
(0.173-0.368)\end{array}$ & $\begin{array}{c}0.258 \\
(0.139-0.377)\end{array}$ & $(-)$ \\
\hline$\rho_{\Delta y}$ & difference of output & $\begin{array}{c}0.357 \\
(0.202-0.503)\end{array}$ & $\begin{array}{c}0.290 \\
(0.133-0.447)\end{array}$ & $(-)$ \\
\hline$\rho_{\Delta \text { ner }}$ & difference of exchange rate & $\begin{array}{c}0.332 \\
(0.176-0.481) \\
\end{array}$ & $\begin{array}{c}0.292 \\
(0.140-0.448) \\
\end{array}$ & $(-)$ \\
\hline$\vartheta^{*}$ & foreign habit & $\begin{array}{c}0.890 \\
(0.851-0.930)\end{array}$ & $\begin{array}{c}0.857 \\
(0.785-0.933)\end{array}$ & $\begin{array}{c}0.888 \\
(0.852-0.923)\end{array}$ \\
\hline$\rho_{r^{*}}$ & $\begin{array}{l}\text { foreign interest rate smooth- } \\
\text { ing }\end{array}$ & $\begin{array}{c}0.734 \\
(0.692-0.776)\end{array}$ & $\begin{array}{c}0.739 \\
(0.671-0.806)\end{array}$ & $\begin{array}{c}0.772 \\
(0.730-0.815)\end{array}$ \\
\hline$\rho_{\pi^{*}}$ & foreign inflation & $\begin{array}{c}1.478 \\
(1.312-1.636)\end{array}$ & $\begin{array}{c}1.483 \\
(1.313-1.645)\end{array}$ & $\begin{array}{c}1.453 \\
(1.296-1.609)\end{array}$ \\
\hline$\rho_{y^{*}}$ & foreign output gap & $\begin{array}{c}0.525 \\
(0.426-0.618)\end{array}$ & $\begin{array}{c}0.475 \\
(0.345-0.604)\end{array}$ & $\begin{array}{c}0.471 \\
(0.356-0.588)\end{array}$ \\
\hline$\rho_{\Delta y^{*}}$ & foreign difference of output & $\begin{array}{c}0.320 \\
(0.167-0.475)\end{array}$ & $\begin{array}{c}0.260 \\
(0.097-0.420)\end{array}$ & $\begin{array}{c}0.284 \\
(0.130-0.447)\end{array}$ \\
\hline$\gamma^{*}$ & $\begin{array}{l}\text { backward looking price } \\
\text { (foreign sector) }\end{array}$ & $\begin{array}{c}0.512 \\
(0.354-0.663)\end{array}$ & $\begin{array}{c}0.617 \\
(0.447-0.801)\end{array}$ & $\begin{array}{c}0.522 \\
(0.361-0.688)\end{array}$ \\
\hline$\psi^{*}$ & price adj. cost (foreign sector) & $\begin{array}{c}43.193 \\
(20.339-65.848)\end{array}$ & $\begin{array}{c}43.577 \\
(21.790-63.545)\end{array}$ & $\begin{array}{c}47.131 \\
(31.427-62.391)\end{array}$ \\
\hline$\kappa^{y^{*}}$ & $\begin{array}{l}\text { foreign marginal cost scaling } \\
\text { factor }\end{array}$ & $\begin{array}{c}0.113 \\
(0.027-0.194)\end{array}$ & $\begin{array}{c}0.176 \\
(0.037-0.323)\end{array}$ & $\begin{array}{c}0.141 \\
(0.068-0.213)\end{array}$ \\
\hline
\end{tabular}

Source: Authors' computations. Posterior means and highest posterior density intervals (in parentheses). The monetary policy rule is 'switched' off in the period after 2009.

The interest rate smoothing parameter of the Taylor rule $\left(\rho_{r}\right)$ captures the relatively steady development of the nominal interest rate in the Slovak economy. It remained so even after the arrival of the euro, when the foreign nominal interest rate smoothing parameter $\left(\rho_{r^{*}}\right)$ in the foreign economy is estimated to have been only slightly higher in the period after the recession than it had been in Slovakia before. The estimates of the interest rate's reaction to inflation are in line with the values suggested by Taylor (1993).

\section{Dynamical characteristics}

The dynamics of the Slovak economy is captured by impulse response functions (IRFs). The impulse responses to a monetary shock that enters the model as an in- 
novation in the Taylor rule are presented in Figure 5 which compares the IRFs of the estimations prior the recession, after the crisis and using the whole time period. Since the Slovak economy has been part of the monetary union since 2009, the foreign monetary shock represents the period of the recession. A positive monetary shock causes an increase in the nominal interest rates. This contractionary monetary policy decreases the output and dampens the CPI inflation. A higher interest rate and a lower inflation also cause an appreciation of the real exchange rate. After a restrictive intervention of a monetary authority, the firms decrease the number of posted vacancies because any additional employees would produce less due to the decrease of the marginal value of jobs at firms. This leads to a decrease of employment in general, be it in the form of a decrease in the hours worked (intensive margin) or the increase of unemployment (extensive margin). The increase of the unemployed and the decrease of vacancies lower the labor market tightness, which in turn causes a decrease of wage inflation. The IRF to monetary shock displays a way through which the monetary authority is able to influence the labor market variables. In the period after 2009, the influence of foreign monetary shock is qualitatively the same; however, its impact is much smaller. This could be the result of the monetary policy of ECB which is not solely targeted on the Slovak economy but a large and heterogeneous group of countries. Furthermore, although Slovakia is a small open economy, shocks originating in the foreign sector are less impactful on the domestic economy. Additionally, as the nominal exchange rate is constant during this period, any changes in the real interest rate are negligible.

Figure 5 IRFs to monetary shock
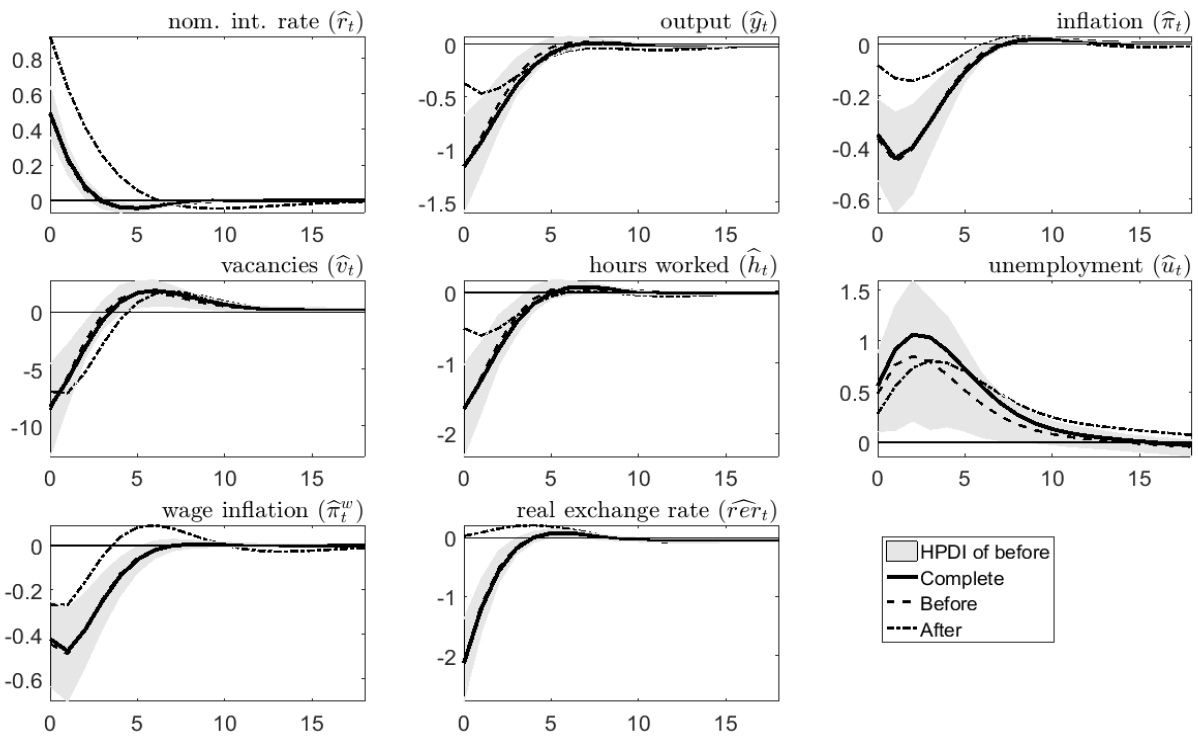

Source: Authors' computations. Note: foreign monetary shock is depicted for the period after 2009. 
Figure 6 shows the IRFs to a technology shock. The initial impact transfers to the increase of output which keeps rising for about a year. After this boom, the economy starts to cool down. The growth of output leads to a decrease of inflation. This drop is more significant in the pre-recession period, when the prices are more flexible. The initial inflow of improved technologies causes a decline in employment unemployment rises while hours worked decrease. Furthermore, the firms lose the incentive to hire more workers, so they reduce the number of offered vacancies. This results in a decrease of the labor market tightness, allowing producers to renegotiate wages at lower levels. Again, due to the higher wage stickiness in the postrecession period, the decrease in wages is less evident. However, after 3 to 4 quarters, the firms need to keep up the increasing production with additional employees. Therefore, they advertise more vacancies (increasing the vacancy rate) and hire more workers (decreasing the unemployment rate). In the period after 2009, due to the higher stickiness, this higher output is sold at higher prices (inflation above steady state) and the revenues are then redistributed among the workers in the form of higher wages (above steady state). To support the growth of the economy, the central bank (in the period before the crisis) reduces the nominal interest rates. The lower inflation and interest rates cause a depreciation of the real exchange rate. Figure 6 also indicates that the technology shock is quite persistent. Several depicted variables do not return to their steady states even after four years.

Figure 6 IRFs to technology shock
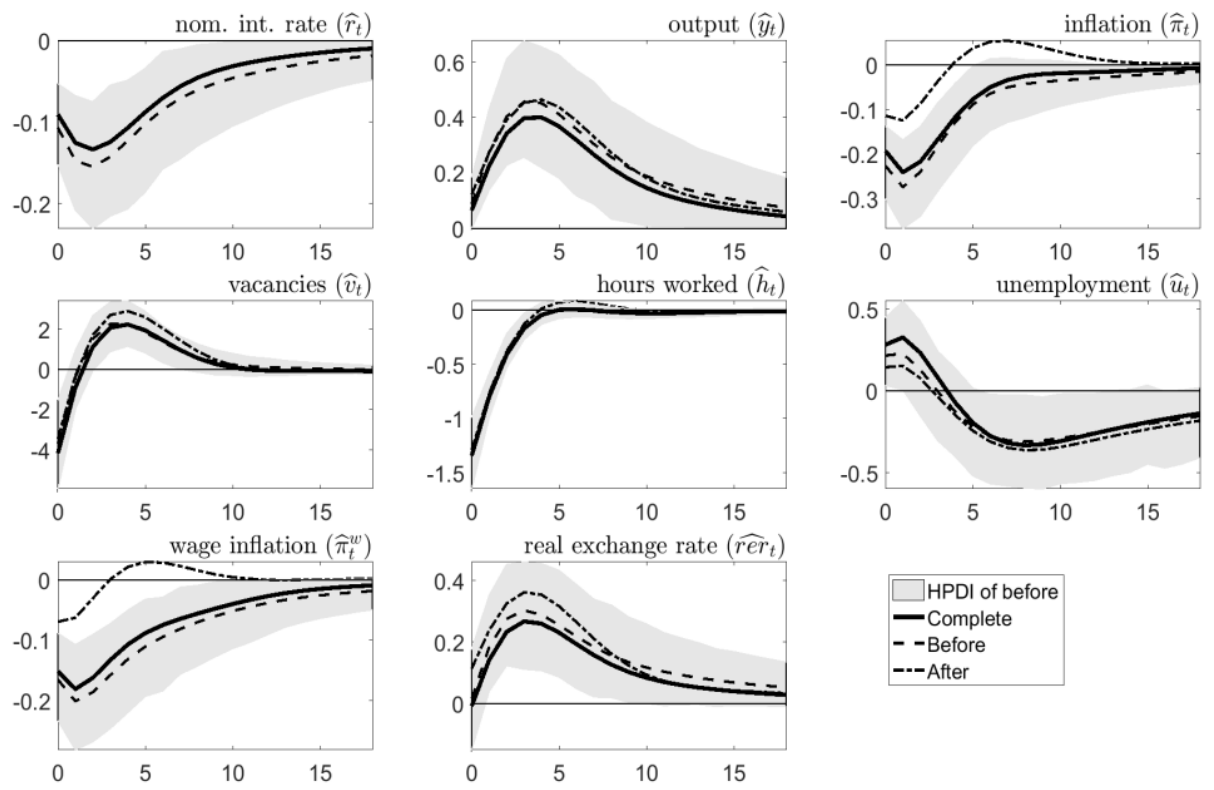

Source: Authors' computations. Note: after 2009, the nominal interest rate is a part of the foreign sector which is not affected by domestic disturbances. 
Impulse responses of variables to a matching shock are captured in Figure 7. The increase of matches is accompanied by a decline of unemployment. The hours worked also decrease because additional employees are hired. The increase of employment and the decrease of hours worked affect the output in opposite directions, and the product therefore initially stays without any change. As the effect of the decrease in unemployment intensifies, the output peaks after six quarters and then starts to decrease. The immediate impact of a matching shock on the vacancy rate is statistically insignificant. The increase of matches results in a significant decline of vacancies after 2 to 3 periods. Hiring new workers causes a decrease of the average hourly wage, which is captured by the decrease of wage inflation. Lower costs and higher output in turn lead to a decreasing inflation. Also, due to the higher wage and price stickiness in the period after the crisis, the change of wage and prices is more substantial before the crisis.

\section{Figure 7 IRFs to matching shock}
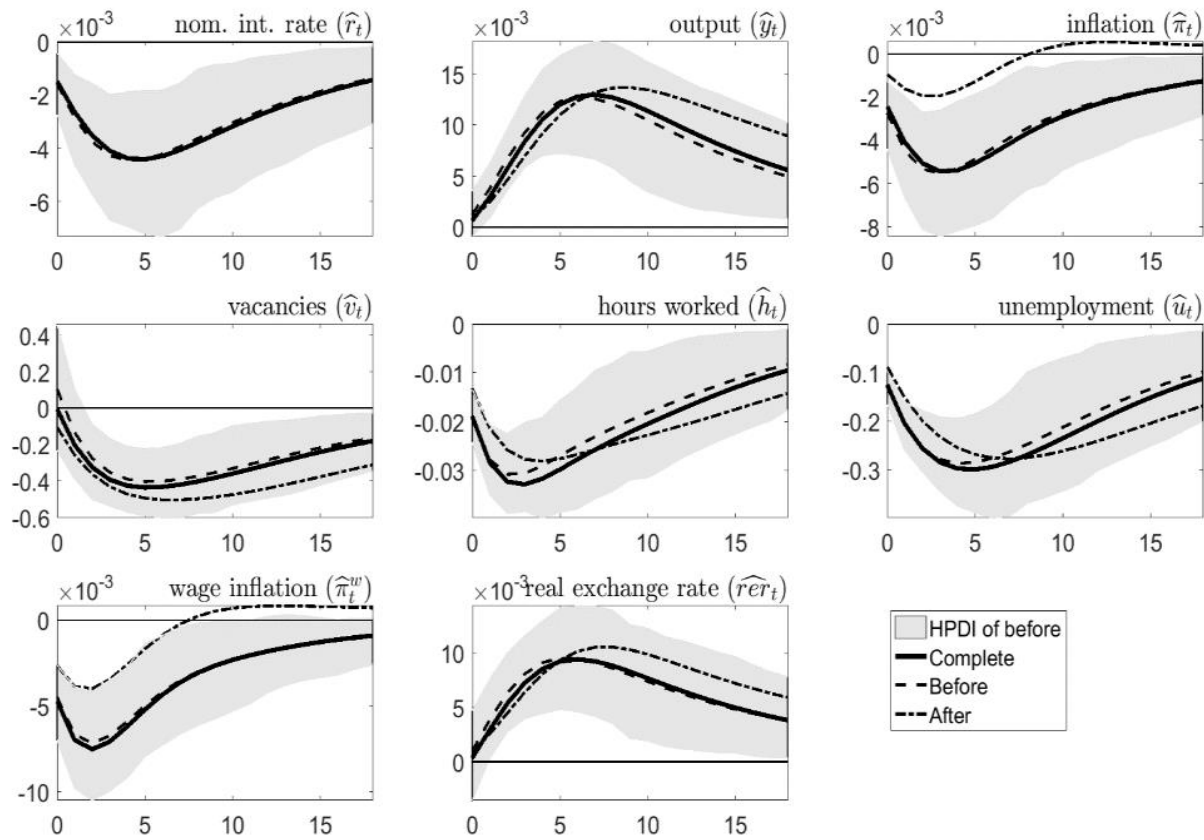

Source: Authors' computations. Note: after 2009, the nominal interest rate is a part of the foreign sector, which is not affected by domestic disturbances.

The positive bargaining shock captured in Figure 8 leads to an increased negotiating power of firms, which allows them to retain more of the generated surplus while keeping the output and prices relatively stable. Firms with higher bargaining power can reduce the workforce by firing less productive or part-time employees (who could, if needed, be hired again thanks to the higher negotiating power). The hours worked of the remaining workforce increases in order to keep up the production. 
The changes in the employment rate lead to an increase of wage. Firms also reduce the posting of new vacancies as keeping an empty job position is costly.

The impulse response functions presented above show that while shocks outside the labor market can influence labor market variables, such as the unemployment rate or wages, the impact of labor market shocks on the rest of the economy is limited. This can also be observed in the next section, where the historical development of selected variables is outlined.

\section{Figure 8 IRFs to bargaining shock}
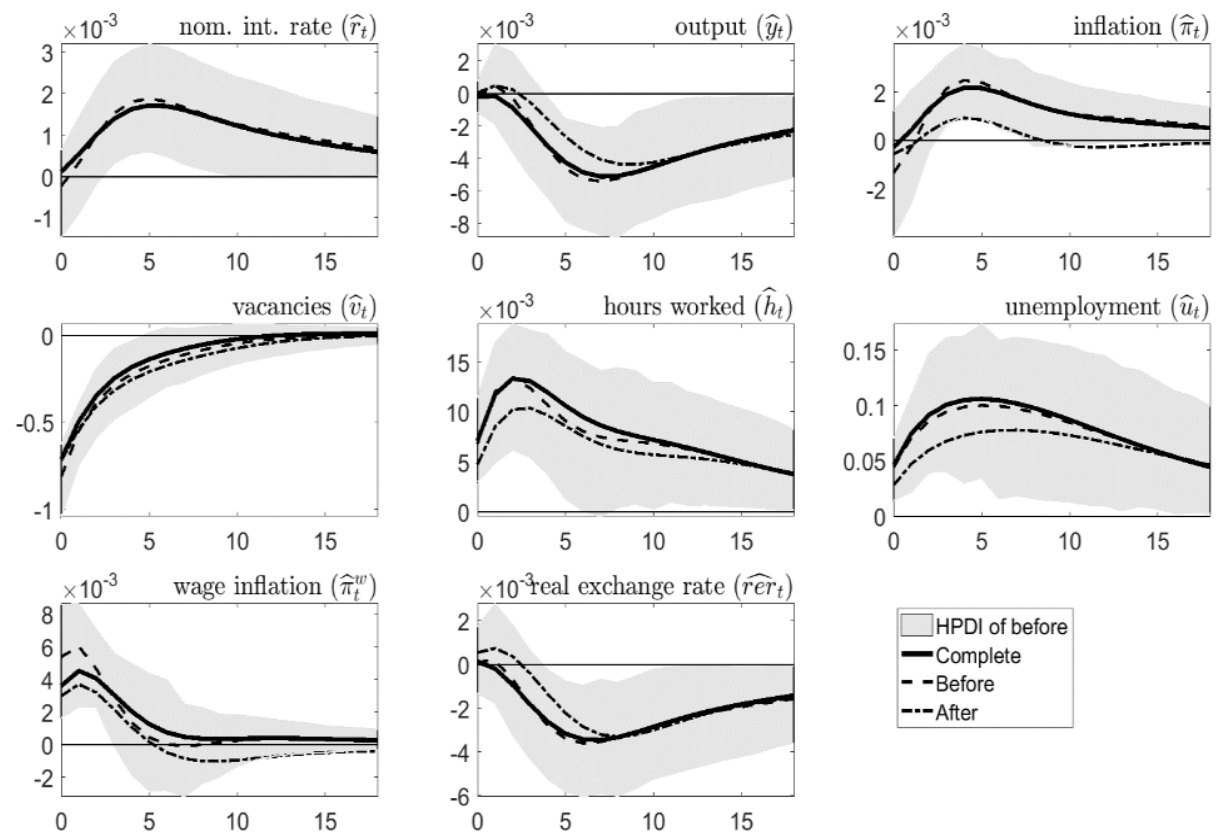

Source: Authors' computations. Note: after 2009, the nominal interest rate is a part of the foreign sector, which is not affected by domestic disturbances.

\section{Historical development}

The historical characteristics are captured through the shock decomposition of selected variables. For a more transparent presentation, these are the three categories of the model's shocks: foreign shocks (shocks to foreign output, inflation and interest rate), labor market shocks (composite of matching, bargaining and disutility from work shocks) and other shocks (the rest of the shocks together with the uncovered interest rate parity shock as in Bergholt (2015)). 
Figure 9 Historical shock decomposition of output

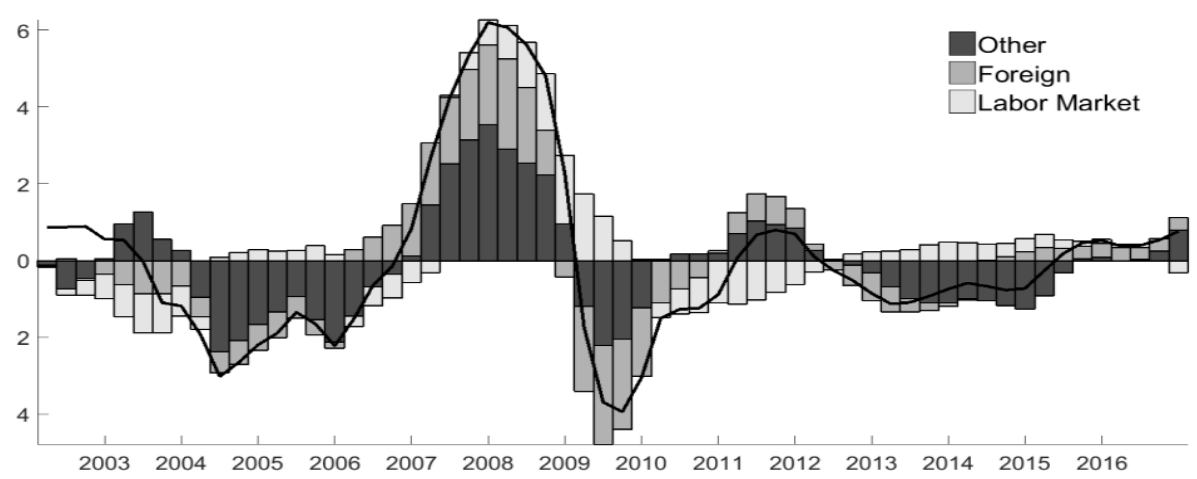

Source: Authors' computations.

The decomposition of domestic output presented in Figure 9 demonstrated the importance of foreign shocks for the small open economy. The Slovak product had, to a great degree, been driven by foreign influences between 2007 and 2010. At first, the positive development in the euro area helped to push the output far above its steady state. However, with the arrival of the recession, the situation changed significantly and the negative effects began to dominate. After the crisis, during 2010 and 2011, the negative effects of labor market shocks also emerged and slowed down the resumption of output to its steady state levels.

Figure 10 Historical shock decomposition of unemployment

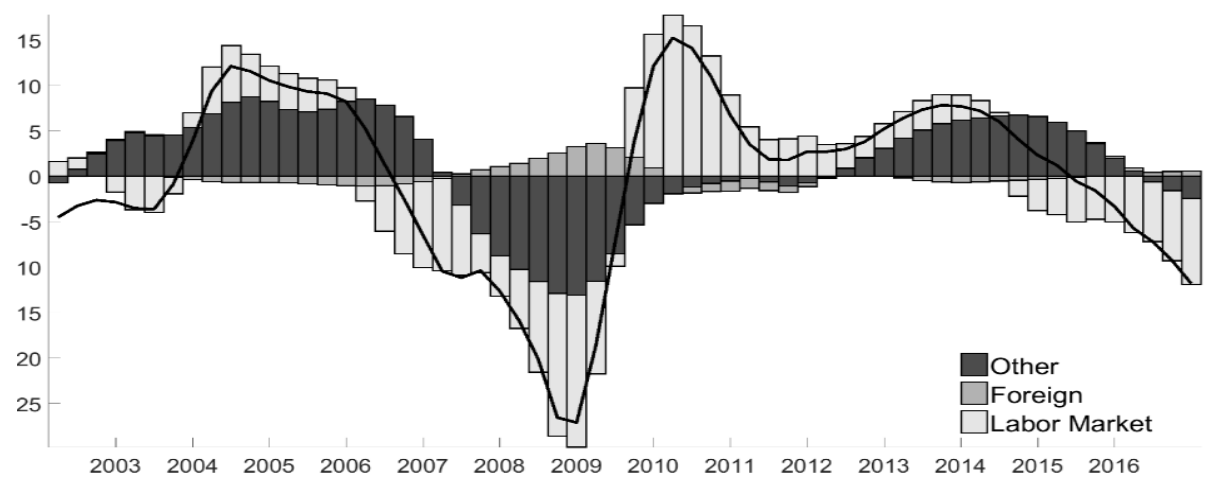

Source: Authors' computations.

Figure 10 illustrates the historical development of unemployment. It is mainly governed by labor market shocks. Unlike in the article by Albertini et al. (2012) where the labor market variables are defined by labor market shocks, here other shocks also play a significant role in the historical evolution of the variable. Foreign shocks are only present around the Great Recession when they encouraged the increase of 
unemployment. At the beginning (2002-2005) and the end (2013-2016) of the examined period, the bargaining and matching shocks influenced the unemployment rate in opposite directions, negating each other's effects. At first, the negative matching shocks had pulled the unemployment up. Meanwhile, the negative bargaining shocks to the negotiating power of firms pushed the unemployment down. The situation is the exact opposite to that in the later timespan, when the effects of the bargaining shock were positive and the influences of the matching shock negative. In the meantime, both shocks first pressured the unemployment downward, and then, with the arrival of the recession, pulled it to higher levels.

The historical shock decomposition of vacancies is captured in Figure 11. Similarly to the unemployment, the influence of other than labor market shocks is also important for the explanation of the development of vacancies. The main influencing factors of vacancies are bargaining, preference and cost-push shocks. In 2002-2004 and 2012-2014 periods, negative cost-push shocks significantly reduced the vacancy rate. On the other hand, positive cost-push shocks in increased the vacancy posting of firms in the 2005-2007 period. This suggests that, in this period, firms invested into the creation of new job positions more. As is apparent from Figure 7, matching shock does not play a noticeable role in the development of vacancies.

Figure 11 Historical shock decomposition of vacancies

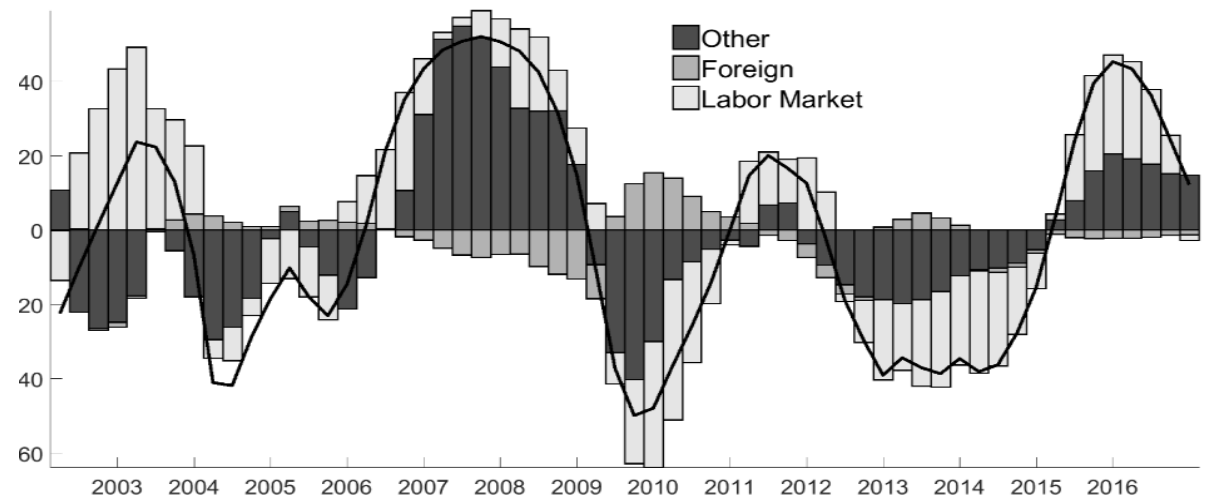

Source: Authors' computations.

\section{Conclusion}

I investigated the dynamical and structural characteristics of the Slovak economy of the past 15 years. The estimated model provides a sufficient description of employment flows in the Slovak economy, and is able to replicate observed data and some of its basic properties.

The structural parameters show that the flexibility of the Slovak economy has declined. This is evident from the rise of the consumption habit parameter, and the domestic goods' price and workers' wage adjustment cost parameters. The latter two are also captured in the data when the increase of both prices and wages was 
considerably slower-moving. Furthermore, the firms' vacancy posting cost is also slightly higher in the post-recession period. The decrease of flexibility is also observable in the different behavior of price and wage inflation as a reaction to a technology shock between the two sub-samples. The model also explains the transmission mechanism of monetary policy shock. Through the channels defined by the model the monetary authority is able to influence the real economy relatively effectively. The effects of changes in the nominal interest rate on the labor market variables are also relevant. The results indicate that the National Bank of Slovakia, and later the European Central Bank, can adjust the development of the Slovak labor market through its monetary policy.

I have also proven that the small open economy of Slovakia has indeed been affected by foreign influences to a great degree. This impact of the foreign sector was evident in the period around the financial crisis of 2008 the most. In the periods between 2006Q1 and 2008Q3, the positive situation in the euro area significantly boosted the domestic economy. However, with the arrival of the recession, the foreign sector had become the main cause of the economic slowdown. The leading causes of fluctuations in unemployment resulted from the changes in the matching effectiveness and bargaining power. Unlike Albertini et al. (2012) or Jakab and Kónya (2016) who in their articles find the labor market variables to be influenced mainly by the labor market shocks, I also describe the important impact of other shocks, such as changes in preferences or costs.

Even though the estimation results provide a considerably stronger link between labor market variables and the rest of the economy than e.g. Albertini et al. (2012) or Jakab and Kónya (2016), this connection still is relatively lower than can be observed in the real economy. Therefore, any future research could cover the analysis of this relationship and should focus on the improvement of the interactions between the labor market and other variables.

Acknowledgements: For helpful comments and suggestions, I would like to thank Daniel Němec who provided insightful notes during the creation of this article. I would also like to thank the two anonymous referees who helped to improve the quality of the paper.

Funding: This work was supported by funding of specific research at Faculty of Economics and Administration, project MUNI/A/0987/2016, by the grant No. GA17$26705 \mathrm{~S}$ of the Czech Science Foundation. This support is gratefully acknowledged.

Disclosure statement: No potential conflict of interests was reported by the author.

\section{References}

ALBERTINI, J., KAMBER, G. and KIRKER, M. (2012). Estimated small open economy model with frictional unemployment. Pacific Economic Review, 17(2). pp. 326-353. DOI: $\underline{10.1111 / \mathrm{j} .1468-0106.2012 .00585 . \mathrm{x}}$

BERGHOLT, D. (2015). Foreign shocks. Working Paper Series, Number: 15/2015. 
BROOKS, S. and GELMAN, A. (1998). General methods for monitoring convergence of iterative simulations. Journal of Computational and Graphical Statistics, 7(4). pp. 434-455.

CALVO, G. A. (1983). Staggered prices in a utility-maximizing framework. Journal of Monetary Economics, 12(3). pp. 383-398. DOI: 10.1016/0304-3932(83)90060-0

GRIFFOLI, T. M (2010). Dynare user guide: An introduction to the solution and estimation of DSGE models. Available from: http://www.dynare.org/documentationandsupport/user-guide/Dynare-UserGuide-WebBeta.pdf.

HODRICK, R. J. and PRESCOTT, E. C. (1980). Postwar U.S. Business Cycles: An Empirical Investigation. Tech. rep. Carnegie-Mellon University. Pittsburgh.

HURTADO, S. (2013). DSGE Models and the Lucas Critique. Banco de Espana Working Paper No. 1310.

CHRISTOFFEL, K., KUESTER, K. and LINZERT, T. (2009). The Role of Labor Markets for Euro Area Monetary Policy. European Economic Review, 53, pp. 908-936. DOI: $10.1016 /$ j.euroecorev.2009.04.007

IRELAND, P. (2007). Changes in Federal Reserve's Inflation Target: Causes and Consequences, Journal of Money, Credit and Banking, 39(8), pp. 1851-1882. DOI: 10.1111/j.1538-4616.2007.00091.X

JAKAB, Z. and KÓNYA, I. (2016). An estimated open-economy DSGE model with search and matching frictions: the case of Hungary. Emerging Markets Finance and Trade, 52(7). pp. 1606-1626.

KALMAN, R. E. (1960). A New Approach to Linear Filtering and Prediction Problems. Transactions of the ASME - Journal of Basic Engineering, 82 (Series D). pp. 35-45. DOI: $\underline{10.1115 / 1.3662552}$

KEEN, B. and WANG, Y. (2007). What is a realistic value for price adjustment costs in New Keynesian models? Applied Economics Letters, 14(11). pp. 789-793. DOI: $\underline{10.1080 / 13504850600592739}$

LUBIK, T. A. (2009). Estimating a Search and Matching Model of the Aggregate Labor Market. Economic Quarterly, 95(2). pp. 101-120.

MORTENSEN, D. T. and PISSARIDES, C. A. (1994). Job creation and job destruction in the theory of unemployment. Review of Economic Studies, 61(3). pp. 397-415. DOI: $\underline{10.2307 / 2297896}$

MÚČKA, Z. and HORVÁTH, M. (2015). Fiscal Policy Matters - A New DSGE Model for Slovakia. Council for Budget Responsibility. Discussion Paper No. 1/2015.

NĚMEC, D. (2013). Investigating Differences between the Czech and Slovak Labour Market Using a Small DSGE Model with Search and Matching Frictions. Czech Economic Review, 7. pp. 21-41.

PFEIFER, J. (2017). An Introduction to Graphs in Dynare. University of Cologne. Available from: https://sites.google.com/site/pfeiferecon/Pfeifer_2014_Dynare_graphs.pdf. 
ROTEMBERG, J. J. (1982). Monopolistic price adjustment and aggregate output. The Review of Economic Studies, 49(4). pp. 517-531.

ROTEMBERG, J. J. (2008). Cyclical wages in a search-and-bargaining model with large firms. In: NBER International Seminar on Macroeconomics, 2006, University of Chicago Press, pp. 65-114.

SENAJ, M., VÝŠKRABKA, M. and ZEMAN, J. (2010). MUSE: Monetary Union and Slovak Economy model. NBS Working paper 1/2010.

TAYLOR, J. B. (1993). Discretion versus Policy Rules in Practice. Carnegie-Rochester Conference Series on Public Policy, 39(1). pp. 195-214. DOI: 10.1016/01672231(93)90009-L

TVRZ, S. and VAŠÍČEK, O. (2016). Structural changes in the Czech, Slovak and euro area economies during the Great Recession. Review of Economic Perspectives Národohospodářský Obzor. 16(4), pp. 297-336. DOI: 10.1515/revecp-2016-0018

ZEMAN, J. and SENAJ, M. (2009). DSGE model - Slovakia. National Bank of Slovakia, WP 3/2009. 